\title{
Energy moves 'still insufficient to meet carbon goals'
}

Tokyo. Japan is unlikely to meet an international commitment to reduce total emissions of carbon dioxide to the 1990 level by 2000 , according to a report released last week by the Environment Agency. But it may be able to keep its already low per capita emissions to the 1990 level.

In 1990, the Japanese government set two different targets of keeping total emissions and per capita emissions of carbon dioxide to the 1990 level (see Nature 347, $700 ; 1990)$. This was a compromise between the strongly differing views of the Ministry of International Trade and Industry (MITI) and the Environment Agency.

The per capita goal, preferred by MITI, is less ambitious and allows for a slight increase in total emissions because of the increase in population. The second, more stringent goal was set in preparation for the 'Earth Summit' in Brazil in 1992, at which developed nations agreed to produce plans for reducing total $\mathrm{CO}_{2}$ emissions to the 1990 level by 2000 .

The Environment Agency's report is based on long-term projections of energy supply and demand made recently by MITI's Agency of Natural Resources and Energy. Providing that it is approved by the cabinet, the report will be submitted next month to the convention secretariat, based in Geneva.

Since 1990, Japan's total carbon dioxide emissions have increased one or two per cent a year. If this trend continues, according to estimates by the Environment Agency, its total emissions will increase by nearly 14 per cent, to 364 million tonnes, by 2000 .

According to the Agency of Natural Resources and Energy, a thousandfold increase in the use of solar power, as well as extensive energy conservation in the home, industry and transport, would reduce $\mathrm{CO}_{2}$ emissions by about 30 million tonnes over this period.

The new Environment Agency report says that, if these goals are achieved, and other measures to reduce energy consumption are implemented, the results would be an increase of only 3.1 per cent on 1990 and a reduction in per capita emissions to 2.6 tonnes per year, the same as 1990 .

Although this level is already one of the lowest in the developed world, some European countries, such as Germany and Denmark, are already talking of committing themselves to even lower targets. The Environment Agency report says Japan must therefore make "added efforts" to stabilize total emissions at the 1990 level. But neither MITI nor Japanese industry, both of which are worried about the impact of restrictions on economic growth, seem likely to support this call.

David Swinbanks

\section{Japan shifts space emphasis towards unmanned missions}

Tokyo. Japan is scaling down its plans for long-term space development to focus particular attention on the Moon and Earth, with a switch of emphasis from manned missions to unmanned observation and exploration. But the plans remain ambitious.

Japan is also planning to propose next month a project to establish an international global Earth observation system with about a hundred satellites. Japan's own proposed contribution is likely to be 20 to 30 Earth observation satellites launched by 2010 .

At the end of last month, the 'special committee on long-term vision', an advisory committee to the Space Activities Commission, submitted its recommendations for the period up to and beyond the year 2020 . These will be used to revise government policy before the end of this year.

The report differs from one published seven years ago (see Nature 327,$645 ; 1987$ ) chiefly in the absence of recommendations for either a manned space station or manned space shuttle to be built by Japan.

The increased emphasis on unmanned missions is in line with the views of the Institute of Space and Astronautical Science (ISAS), the smaller of Japan's two space agencies, which has achieved international recognition for its relatively modest scientific missions.

The report calls for systematic exploration of the Moon, using satellites and remote-controlled vehicles, with the aim of establishing an unmanned astronomical observatory between 2010 and 2020 . This contains elements of recommendations for a Moon base published in June by the Lunar and Planetary Society (see Nature 369, 435; 1994), but with the key difference that the observatory will not be manned.

The proposals for lunar exploration over-

lap with plans of the European Space Agency. The report calls for international cooperation in establishing the lunar observatory, and Japanese space scientists say they hope to cooperate with Europe in lunar exploration, if the Japanese and European proposals are approved by their respective governments.

Smaller missions to the Moon and nearby planets, such as Mars and Venus, will be launched with the solid-fuel $\mathrm{M}-\mathrm{V}$ rocket currently under development by ISAS. Larger missions, and missions to more distant planets such as Jupiter, will be handled by the new liquid-fuel H-II rocket of the National Space Development Agency, launched successfully for the first time earlier this year.

The report calls for the development of a larger H-II rocket, with double the payload capacity of the present version. This would be able to put a satellite weighing four tonnes into geostationary orbit, and would also be able to launch the 20-tonne unmanned space shuttle HOPE, expected to be built by the end of this decade.

The report's proposals will, if adopted, require an investment of $¥ 7,000$ billion ( $\$ 70$ billion) over 15 years from 1995, with a consequent increase of nearly 10 per cent a year in Japan's current space budget of about $¥ 200$ billion.

This is an ambitious target, given the severe fiscal restraint policies of the Ministry of Finance, particularly during the current recession. But the space budget has recently been increasing by between eight and nine per cent per year, largely as a result of Japan's contribution to the US Space Station. The new budget requirement is therefore well within the realms of possibility.

David Swinbanks

\section{Olympic science gets $\$ \mathbf{1} / 4$ million prize}

London. The International Olympic Committee (IOC) has announced the launch of a new prize intended to recognize "the evolution of scientific research related to human development". The prize, sponsored by the pharmaceutical company Parke-Davis, will include a medal and cash sum of $\$ \mathbf{2 5 0 , 0 0 0}$.

The IOC Olympic Prize will be awarded every two years for research in the biological, medical, physical or psychological sciences. The first winner (or winners) will be announced at the 26th Olympic Games, which take place in Atlanta, Georgia, in 1996.

Meanwhile, French mathematicians, worried at signs that their traditional impact on world science may have been decreasing in recent years, are celebrating the award of Fields Prizes - the discipline's equivalent of the Nobel Prizes - to two of their colleagues, Pierre-Louis Lions and Jean-Christophe Yoccoz.

The third Fields winner, Jean Bourgain, although a native of Belgium, has lived in France for many years, and combines positions at the Institut des Hautes Etudes Scientifiques outside Paris and the Institute for Advanced Study at Princeton University in New Jersey. The fourth winner is the Russian-born Efim Zelmanov, now at the University of Chicago. 